\title{
Branded Apps in Spain as a Means of Communicating Trends in Fashion
}

\author{
http://dx.doi.org/10.3991/ijim.v10i2.5558 \\ Z. F. González Romo ${ }^{1}$, R. Contreras-Espinosa ${ }^{1}$ and I. García Medina ${ }^{2}$ \\ ${ }^{1}$ Universitat Central de Catalunya - Universitat de Vic, Vic, Spain \\ ${ }^{2}$ Glasgow Caledonian University, Glasgow, United Kingdom
}

\begin{abstract}
Apps are of great interest and curiosity for the users of mobile phones, being already highly unloaded and used for the users of smartphones.

The fashion mobile applications represent only a fraction of the mobile global applications (almost $0,2 \%$ ), nevertheless they are starting to deserve special attention from designers and researchers in this area. Brands want to know about the new trends in the market to be able to continue surprising and impressing their public.
\end{abstract}

In this study, we seek to identify the most relevant aspects of the applications that help to improve the image of the Spanish prêt-à-porter fashion brands such as Zara, Pull and Bear, Stradivarius, Shana, Bimba y Lola,...

The study considers the position in the ranking of downloads, the category, the opinions, valuations of the users and the criteria described by Jami Lawrence (2010): amusement, saving of time and / or comfort in the use.

Index Terms-apps, fashion apps, mobile-media, users, mobile applications

\section{INTRODUCTION}

Apps are small programs for smartphones. Generally they are grouped by subject or functionality: for business, for city living, for free time, apps are useful to play and to entertain, for the house, for trips and useful apps also for health and well-being (Clark, 2009:37). Shops that offer apps provide both free and pay-for applications, some platforms only offer one of the two types. The AppStore from Apple offers 333.214 apps, but less of 150.000 are free. Similarly, in Blackberry App World 26.771 applications are on offer but only a third are free. In the current market users prefer free apps and it seems that this trend continues increasing. According to information of a study from IHS's Screen Digest, $96 \%$ of all the applications for smartphones that were unloaded in 2011 were free (Using eMarketer, 2012a, par. 1).

\section{THEORETICAL AND CONTEXTUAL IMPLICATIONS}

\section{A. Branded App}

Some researchers consider that branded apps "differ from traditional online and mobile advertising, such as pop-up or banner ads, in that users, not advertisers, choose to continue using the apps" (Kim, Lin \& Sun, 2013, p. 54). and conceptually they are defined as a software to download a mobile unit that helps to identify a brand and to construct its identity. That can be done across the name of the application, the appearance of an icon of the app or via the user experience (Bellman, Potter, TreleavenHassard, Robinson, \& Varan, 2011, p. 192).

The study of Bellman et al., also suggests that the most successful type of app is the one that is the most intensive to produce. Designing app that consumers find useful in their daily lives is a lot more difficult than building an experiential app by creating or adapting an interactive game: it requires developing a whole suite of tools instead of just one. Identifying, programming, and testing these tools require a large budget of time and money to ensure success. (Bellman et al., 2011, p. 192).

Probably one of the reasons of the high popularity of the branded apps in the area of marketing is the enormous capacity of engagement and the positive impact that presumably the apps have on the attitude of the users towards the brand (Hutton \& Rodnick, 2009, p. 23). There are studies that complement these opinions saying that interactivity and the experience that the user experiences during the use of the application are possible reasons for the demand of branded apps (Calder, Malthouse \& Schaedel, 2009, p.326).

Some research has revealed that among some of the most important attributes to capture engagement include: vividness, novelty, motivation, control, customization, feedback, and multi-platform capability (O'Brien \& Toms, 2008, p. 3). Specifically, the studies from Kim, Lin and Sung demonstrate that these global brands provide mobile environments in which "their branded app users can easily 'control' all the views within the apps". The users are able to navigate through an app by means of on screen app interfaces adapted to mobile device touch screens. (Kim et al., 2013, p. 60)

There are other relevant studies such as the one from the Mobile Marketing Association - MMA (2001b, p.20), which carries out a typology, centered in branded apps, so much to the level of communication as of the level business, and explain the aims that any app must chase:

a) The app must be a generator of notoriety and brand image; across contents, uses and experiences using the apps, it is possible to generate a positive image of the brand and create good aptitudes and positive behaviors of the users.

b) The app represents loyalty of users and customers; apps have turned into a new suitable channel for companies, with the possibility of being a way of permanent and personalized communication between clients and brands. Thus a link is created that can strengthen the relation between the company and the consumer influencing his decisions and also the frequency of purchase. 
c) The app as a management tool; the applications designed for companies can be excellent management tools, quality control tools, and also they are important for follow-up work and management of knowledge across databases or in direct.

d) The app as a sale tool (Mcommerce); the applications can be designed by sale services, which is another channel for the brand to sell their products or services. The mobile applications of sale can complement with other sale tools online or offline or if the product / service allows it, to be an exclusive channel of sale.

e) The app to generate income; several highly successful applications generate direct income for its developers or publishers. In the business models of the applications, it is possible to commercialize advertising spaces in the app, as well as put a price to the application, be able to be unloaded, or carry out purchases in-app as for example: the sale of digital goods, virtual currency, the subscription to contents or the purchase of extensions of the own app. (Using Mobile Marketing Association, 2011b, p.21).

Apps are of great interest and curiosity for the users of mobile phones, being already highly unloaded and used for the users of smartphones, that it is why the brands want to be also present in the world of the applications and to manage his brand across them (González \& Contreras, 2012, p. 82). Brands want to know about the new trends in the market to be able to continue surprising and impressing their public.

One of the factors that contributes to the diffusion and knowledge of the applications it is the word of mouth, the prescription of the circle of friends and acquaintances is the channel of information most appealed when we talk about applications for mobile, probably linked to the almost universal penetration of the device, which it facilitates in turning it into object of conversation (Using IAB Spain Research, 2012, p. 47)

\section{B. Apps Inside Strategic Plans of Communication}

Mobile applications are a format with growing popularity but it does not mean that all the brands have to have apps, it is important to take into consideration the type of public whom it is directed the product, what uses they do with their mobile phones, if they have a smartphone. In some cases quality customer-company dynamics contributes to a satisfactory in-store shopping experience, and lacking this social element in virtual retail contexts can be a critical negativity (Lee \& Hahn, 2015, p. 145). Marketers should bear in mind the importance of the aims of the brand and the best way of communicating these messages to the public (Snyder, 2009, par. 4).

We cannot ignore the fact that online consumers have the limitation of product experience and evaluation, due to the inability to directly experience the product, thereby increasing perceived risk of product performance. (Yul, Lee \& Damhors, 2012, p. 260). Kim et al. (2013, p. 55) highlight the interest of analyzing the message strategies between product and service branded apps. The results of their research showed that informational message strategies were more frequently employed by service branded apps than those of product brands and just the opposite for transformational message strategies.

The following step in this new space of bilateral communication between the brand and the client is the production of a coherent strategy and to guarantee to the user a complementary and consistent experience with the brand. In other words, the application does not have to be a separated entity from the general image of the brand and must be integrated with other tools of communication developed by the brand. (González \& Contreras, 2011, p. 86).

\section{Fashion Apps}

Fashion mobile applications represent only a fraction of the mobile global applications (almost 0,2\%) nevertheless they are starting to deserve special attention from designers and researchers in this area. Whereas other dimensions of the daily life have benefited from the development of mobile applications, fashion still uses the apps in a very limited way. This has happened due to the general delay that the fashion world as an industrial sector has showed in the exploitation of the whole potential of the new technologies of the communication and the information (Nie \& Fortunati, 2013, p. 17).

The focus centers now on fashion applications that represent an important contribution to the renovation of the system of fashion (Kawamura, 2005). In today's fashion applications information is transmitted between the fashion industry and the fashion consumers, as well as the fashion services that help people to be kept informed, to choose, to buy and to adopt fashion offers in their daily life. The apps seem to have the aptitude to offer new solutions for the problem of this integration (Nie \& Fortunati, 2013 , p. 2). In addition, the mobility of the smartphones plays an important role in the opportune fashion exchange in the street, allowing the users to break geographical limitations, something that would be impossible with a desktop computer and that instead share attributes with the Internet, as the easy accessibility, interactivity and his potential of networking. (Nie \& Fortunati, 2013, p. 2).

It is easy to understand the relevancy of fashion in social life, where style is constructed as a form of experience of the masses and where users need to relate fashion goods to the material dimensions of their personal habits, tastes, practices, etc. (Nie \& Fortunati, 2013, p. 17). Mobile technology has given a radical change with regard to the communication of the traditional unidirectional fashion (from the design to the users across the traditional media) to a new relation two-way/many-to-many. Developers now use the apps to persuade and to guide users who give their feedback rapidly and, at the same time, and after receiving the feedback of the users, developers can react rapidly. The whole system of bidirectional communication works in an efficient way in the platforms of fashion applications.

To take advantage of the advantages of this new context, the world of fashion must increase its comprehension of how to adopt and monetize new mobile technology. This comprehension will allow them to open effective channels of communication with the potentials consumers of fashion, not only with the intention of informing the users about their new offers in a more efficient way, but also in order to receive opinions of the users and suggestions.

\section{METHODOLOGY}

For this qualitative exploratory study, the first aim was to identify the sources of secondary information that were allowing to gather directly information of the sector. For it, we have selected a sample of Spanish applications for iPhone provided by Apple Store Spain, under the classifi- 
cation "Top free ". The analysis of the applications was carried out between February 12 and March 9, 2013, and included 10 mobile applications.

The analyzed sample consists of applications corresponding to 10 Spanish fashion brands classified in the shop under the concept "Ways of life". Because this is an exploratory study, the 10 apps analyzed were framed in the first sites of popularity and it comes out into the App Store of Spain, the selection of these apps has been done taken into consideration that they are inside the most popular 100. The size of reduced sample was considered because in exploratory studies limited samples are used because they are previous actions that help to design later investigations with more extensive samples and because they fulfill a function of intellectual preliminary stimulation (Corbeta, 2007, p. 234).

It is necessary to mention that not all the recognized brands or prêt-à-porter fashion have an app available to download in the "Ways of Life" section in the App Store. The majority of applications that the shop facilitates are created for the management of daily actions but they do not link themselves specifically to a specific brand or fashionable brand. The selection of the apps is being limited only to applications linked to a mobile web of a Spanish brand of prêt-à-porter, rejecting therefore foreign brands or related to lingerie or distributors of product or intermediary.

The 10 Spanish prêt-à-porter fashion brands are: (download ranking) Zara (9), Pull and Bear (13), Mango (17), Bershka (21), Stradivarius (28), Massimo Dutti (40), Bimba y Lola (43), Shana (56), H.E. By Mango (90), Uterqüe (92). A classification has been created to gauge the consistency of the app with the marketing aims of the brand. The suggested classification includes aspects such as whether Mcommerce is available or not, the opinions of the users, and to complete this evaluation. The evaluation was assigned to each app by the authors of this paper who have used the apps regularly during a period of four months.

These factors have been considered: The app, and the brand that it represents, the position that the app occupies in the top 100 downloads, the category of the application, the valuation granted by the users in every case (Figure 1), the opinions and comments of the users to value the engagement and the language that is used. The valuation given by the users is reflected "spider web" charts. These represent an estimation granted depending on the use, usefulness and success of the application.

This process of information was complemented with a study of bibliographical sources that show the observations of theoretical experts, marketing managers and reports on the mobile market. It is necessary to mention, that far from the statistical representation of the results, we will like to make more visible an area little explored until now. Applications were analyzed using different mobile devices: iPhone 3GS (iOS 6.0) and iPhone 4 (iOSx).

\section{RESUltS AND Discussion}

Table 1 shows the 10 apps of the brands analyzed, the applications have been organized under the search criteria "Ways of life" Top free.
TABLE I.

POSITION IN THE DOWNLOAD RANKING OF BRANDS ANALYZED

\begin{tabular}{|l|c|}
\hline \multicolumn{1}{|c|}{ Brand } & Position in the ranking \\
\hline ZARA & 9 \\
\hline PULL AND BEAR & 13 \\
\hline MANGO & 17 \\
\hline BERSHKA & 21 \\
\hline STRADIVARUIS & 28 \\
\hline MASSIMO DUTTI & 40 \\
\hline BIMBA Y LOLA & 43 \\
\hline SHANA & 56 \\
\hline H.E. BY MANGO & 90 \\
\hline UTERQÜE & 92 \\
\hline
\end{tabular}

\section{A. Position in the Ranking}

The first of the criteria to analyze is the download ranking of the apps. Inside the Top free, with better positioning we can find the Zara application, followed of the brand Pull and Bear belonging to the same company (Inditex) and for Mango of the eponymous company. The factors that influence the position of the ranking depend on the number of downloads, time of use, number of times that the app is opened, number and score in the valuations. Most of the criteria are more related to the obtained engagement that to the number of downloads. On having added these criteria in the rankings the app stores are reflecting the importance of which the users continue using their apps after the download.

If the user uses the app frequently it means that the app is designed correctly and it is useful for the user. It increases the possibility of generating income with upgrades, buys of other applications that the brand is throwing and / or if it is focused on the mobile commerce, with direct sales from the own application (Elósegui, 2013, par. 32).

The user will recommend the app to his contacts. The application will improve its positioning in the different rankings of the app store. The number of downloads can be increased by advertising campaigns when the app is free, but to generate engagement, the user needs to know the characteristics of the app before downloading it. And we will obtain this based on good content. As is explained by Nie \& Fortunati (2013, p. 12): "The most often shared experiences are those related to the content of the application, the application functions, and assessment of how easy it is to use it, to the use of the application in their everyday lives, and in very few cases to advertising information".

The position in this ranking, therefore, is owed to the quantity of downloads of the application, and how it functions, which allows that his position should improve depending on the times that the above mentioned application is in use. Zara occupies the first position, curiously an application that lacks valuation on the part of the users in stars and in comments, but that has been mentioned in the valuations of other applications as the perfect application: " The application works badly (talking about Bershka's app), it does not work correctly like that of Zara, which is perfect. " 


\section{B. Mcommerce and Branded Apps}

The following criteria of analysis are to identify if the application has Mcommerce. We have identified that all the downloaded applications have this service (Cited as Table II), that is to say, they are applications that allow the purchase of products directly from themselves and that reinforce the experience of the brand. In studies carried out previously by the researchers the results of the users of the applications, expressed in the opinions were showing that not to have a space of purchase was detected as a problem from the users (González \& Contreras, 2011, p. 82). The principal complaint in case of the applications of the above mentioned study was that one could not purchase products via the app, the lack of Mcommerce's space, in the majority of examples checked at the time, was showing that it was necessary to go out of the application and to go to the web page to carry out the purchase, which was forcing the user to develop a series of extra steps that were slowing down the process of purchase. Apparently the Spanish fashion apps analyzed have taken note of these faults and in their sales since we saw in some opinions: "I am charmed with this app, it is brilliant, it is good to be able to buy clothes so easy without any problem, so I am going to give them 5 stars, I love it, download it! " Talking about the app of the brand Stradivarius.

\section{Score and Users'Opinions}

In addition we have included the valuation in "stars" that go from one to five and it is assigned by the users as well as the number of opinions received for every app (Cited as Table III). After downloading an application, users are usually asked to rate, from "one star" to "five stars", the application on the webpage of the application store: 1 star means "hate it"; 2 stars mean "don't like it"; 3 stars mean "it's OK"; 4 stars mean "It's good"; 5 stars mean "it's great". Rating scores correspond to the average star rating given by users after they download these applications.

In contrast to what has been observed in another type of applications, and in the particular case of the Spanish prêtà-porter fashion applications: It is not possible for users to leave reviews. Apparently the users think that an application must work correctly, and if it is like that, they avoid giving their opinions, though when the application does not work correctly they are in the habit of comparing it with those that are relating in usability: "As ZARA is also part of the Inditex group, it is incomprehensible why they do not use the same application, with the whole updated and detailed collection, as well as the price " (comment issued on Bershka's application).

The opinions are centered especially on the critique of the application, this way we can observe in case of two very badly rated applications: Mango and Bershka. Nevertheless these apps have the most opinions left by users. Both these badly rated applications have a considerable number of opinions with regard to the rest of analyzed applications, opinions that in all the cases turn out to be negative, 8 in case of Mango and 15 in case of Bershka, the phrase " does not work " it has been one of the most repeated. In case of the Mango application, which although it is described on the app store as being complete and well developed with the possibility of on-line purchase, it was not possible to verify it because to the investigators also found it has been impossible to access to the app via various devices. In this case it is a defective tech-
TABLE II.

MCOMMERCE

\begin{tabular}{|l|c|}
\hline \multicolumn{1}{|c|}{ Brand } & Mcommerce \\
\hline ZARA & YES \\
\hline PULL AND BEAR & YES \\
\hline MANGO & YES \\
\hline BERSHKA & YES \\
\hline STRADIVARUIS & YES \\
\hline MASSIMO DUTTI & YES \\
\hline BIMBA Y LOLA & YES \\
\hline SHANA & YES \\
\hline H.E. BY MANGO & YES \\
\hline UTERQÜE & YES \\
\hline
\end{tabular}

TABLE III.

APPS ANALYZED AND THEIR SCORE

\begin{tabular}{|l|c|c|c|}
\hline \multicolumn{1}{|c|}{ Brand } & $\begin{array}{c}\text { Score } \\
\text { stars }\end{array}$ & $\begin{array}{c}\text { Positive } \\
\text { Opinions }\end{array}$ & $\begin{array}{c}\text { Negative } \\
\text { Opinions }\end{array}$ \\
\hline ZARA & NONE & 0 & 0 \\
\hline PULL AND BEAR & 3,5 & 4 & 2 \\
\hline MANGO & 1,5 & 0 & 8 \\
\hline BERSHKA & 1 & 2 & 15 \\
\hline STRADIVARUIS & NONE & 1 & 0 \\
\hline MASSIMO DUTTI & NONE & 0 & 1 \\
\hline BIMBA Y LOLA & NONE & 0 & 1 \\
\hline SHANA & NONE & 0 & 0 \\
\hline H.E. BY MANGO & NONE & 0 & 2 \\
\hline UTERQÜE & NONE & 0 & 0 \\
\hline
\end{tabular}

nological application and failures in the updates are what has deteriorated the brand.

Bershka's application suffers equally from technical issues. It crashes constantly, as express by the users: " You can enter but when you are waiting for the catalog to load it closes ", " always closed and you lose what you have in the basket ", "It is not possible to see the clothes because it closes by itself ", " I downloaded the application and when I open it for the first time it is OK, but after I close it, I cannot open it again, so I have to take it away and reinstall it. It is exasperating. Solutions please!! "

And though it provides access to the online shop, it turns out to be impossible to carry out any type of electronic transaction: "very bad, it is not possible to buy by Internet", "Please, repair the application, it works really badly. It is possible to see the clothes but not to buy them. What a disaster!". This reverberates evidently in the image of the brand and this way it is expressed by users: " It is the worst application of all those of the Inditex group, the difference that exists between this and some and others is incredible. I am employed at Bershka and I feel ashamed when they ask me. Painful!", "Not bad, the worst! ", "The most useless thing in the world."

\section{Languages Used by the Apps}

Finally, the last of the analyzed criteria has been the languages in which the application is presented to the user, in general, the applications of the fashion brands are developed in Spanish language, though in this respect we find singularities: the case of Massimo Dutti and Bershka, both they offer the application in 4 official languages 
(Spanish, Catalan, Galician, Basque) and in English. Mango H.E. has geolocation. If the application is used in Catalonia, the app is presented in Catalan although it gives the option to change the language. When entering the Uterqüe app, the user is asked if English or Spanish is preferred.

\section{CONCLUSIONS}

As general conclusions, on the basis of the obtained results, we can mention the fact that in order that an application is valued correctly, and the brand is perceived by their public in a positive way, there are some factors to take into consideration: It is indispensable that the applications entertain the user, save time and / or comfort, we have observed that they are these characteristics those that are valued by the users.

Another factor that is valued in the applications, is that the application should make sense for the user and to have an added value that doesn't necessarily have to be related with the nature of the brand. But it is important that applications to be developed have to be coherent with the identity of the brand. As in any other area, the appearance of new mass media, like the mobile, is the introduction of new challenges. Finally, it is important for the brand to adapt constantly to the new technologies, but we must not forget that a precarious incorporation and badly developed app it can be more harmful than beneficial.

In this analysis, we seek to identify the most relevant aspects of the applications that help to improve the image of the brand, in this particular case of the Spanish prêt-àporter fashion brands. The study considers the position in the ranking of downloads, the category, the opinions, valuations of the users and the amusement, saving of time and / or comfort in the use. It observes that the best identified fashion applications are those of Zara, Pull and Bear, Stradivarius and Shana because they fulfill with the following criteria:

\section{A. Interface}

The interface has to generate notoriety and brand image across the contents, usefulness and experiences of the users (Using MMA, 2011b., p. 30). It is possible to generate this way a positive and viral effect. All the components - text, photographs, images, maps, sounds, videos of the interface that transmit information are considered. Aspects as the feedback, the functions, identification and quality were evaluated by the equipment of research that observed that the mentioned applications show a simple, visual and clear interface, the navigation is simple and always it is possible to return to the point of item. All of them show photos in high quality of the products and the products showed in the catalog coincide with that they can find in the shop, which favors the experience of the users and reverberates in the image of the brand. In some cases the applications are offered in 4 official languages (Spanish, Catalan, Galician, and Basque) and in English.

\section{B. Mcommerce}

All of them offer the possibility of purchase, the action of purchase is simple and the Mcommerce works without problems. The purchase is a simple and rapid process that allows to the user to keep for some time the articles selected to buy them later. In fact the MMA in his last studies recommends in his typology of Branded apps the use of these spaces as tool and channel of sale.
TABLE IV.

LANGUAGES OF THE APP

\begin{tabular}{|c|c|}
\hline Brand & $\begin{array}{l}\text { Languages used in } \\
\text { Spain for App }\end{array}$ \\
\hline ZARA & Spanish \\
\hline PULL AND BEAR & Spanish \\
\hline MANGO & Technical problems prevented access \\
\hline BERSHKA & $\begin{array}{l}\text { Spanish Catalan } \\
\text { Galician } \\
\text { Basque } \\
\text { English }\end{array}$ \\
\hline STRADIVARIUS & Spanish \\
\hline MASSIMO DUTTI & $\begin{array}{l}\text { Spanish Catalan } \\
\text { Galician } \\
\text { Basque } \\
\text { English }\end{array}$ \\
\hline BIMBA Y LOLA & Spanish \\
\hline SHANA & Spanish \\
\hline H.E. BY MANGO & Spanish Catalan \\
\hline UTERQÜE & Spanish English \\
\hline
\end{tabular}

\section{Information}

All the applications provide complete information about their products, besides possessing a space where the innovations appear. Zara's applications, H\&M, Uterqüe and Bimba y Lola, have introduced the latest technology, as the geolocation and show the options of location of nearby shops.

In addition the apps present actual information, gallery of photos and the possibility to share comments. In addition, the quality of the information and services included in the applications were analyzed: the available stock of the desired products in case the user wants to purchase the product from a store, different information about the location of the shops (maps), and additional information (exhibitions, events, etc.) the applications of Zara, Uterqüe and Bimba y Lola, they have introduced the latest technology such as geolocation. This offers a service of added value to their clients (Using MMA, 2011b., p. 31). Though the analyzed applications do not possess a central structure because they do not include links to the official web, the purchase and navigation are centered strictly on the same application that has turned into a mobile web. The future investigations should explore if this technological disconnection implies also one communicative disconnection.

\section{Content}

Though the 4 applications valued like the best (Zara, Pull and Bear, Stradivarius and Shana) show all the products like catalogs, they do not limit themselves to showing the product only, but they enrich the apps with contents that can be interesting for their public. With this type of contents we refer to specific spaces inside the apps that they allow a major definition of the user's profile depending on their needs, a series of filters adapted for the correct search and contributions of the brand like "Top sales", "Look Book" or "last week", which they allow a constant utilization of the application to the user what derives in a better positioning and make the clients more loyal.

Taking into consideration the origin of the contents of the apps, it is possible to identify: adapted and re-used 
contents. In the context of the investigation the researchers were centered on two variables: contents adapted (in general from the brand) and contents generated by the users. Their aim is to make users and clients as a suitable channel more loyal (Using MMA, 2011b., p. 30). But in the apps analyzed this aim is not fulfilled completely, because none of them take into consideration the production of content by consumers and they choose a model based on the transmission of information. The incorporation of content generated by users can be a cheap solution to overcome the costs of developing information for the users.

It is necessary, to conclude, to add that this study does not try to present the necessary values in order that the brand is managed correctly in the applications, it tries to be an approximation to the current reality and we try to mark some guidelines for the correct management in the identity of the brands with a view to the best perception of the brand from its public. What leads to the conclusion of which as well as there is no a device for all, no platform is adapted for all the brands if it does not form a part of a correct strategy of management of the brand.

\section{REFERENCES}

[1] Clark, J. (2009). Best iPhone apps :The guide for discriminating downloaders. Sebastopol, CA: O'Reilly Media.

[2] eMarketer (2012a, January 27). Free apps win out over paid downloads [Web log post]. Retrieved from http://www.emarketer.com/Article.aspx?R=1008796HYPERLINK "http://www.emarketer.com/Article.aspx?R=1008796\&ecid=a650 6033675d47f881651943c21c5ed4"\&HYPERLINK

"http://www.emarketer.com/Article.aspx?R=1008796\&ecid $=\mathrm{a} 650$ 6033675d47f881651943c21c5ed4"ecid=a6506033675d47f881651 $943 \mathrm{c} 21 \mathrm{c} 5 \mathrm{ed} 4$

[3] Kim, E. Lin, J. \& Sung, Y. (2013). To App or Not to App: Engaging Consumers via Branded Mobile Apps. Journal of Interactive Advertising, 13(1), 53-65. http://dx.doi.org/10.1080/15252019. 2013.782780

[4] Bellman, S., Potter, R., Treleaven-Hassard, S., Robinson, J. \& Varan, D. (2011). The Journal of International Marketing, 25, 191200. http://dx.doi.org/10.1016/j.intmar.2011.06.001

[5] Hutton, G. \& Stu R. (2009). Smartphone Opens up New Opportunities for Smart Marketing. Admap, 44(11) 22-24.

[6] Calder, B., Malthouse, E. \& Schaedel, U. (2009). An Experimental Study of the Relationship between Online Engagement and Advertising Effectiveness. Journal of Interactive Marketing, 23(4), 321331. http://dx.doi.org/10.1016/j.intmar.2009.07.002

[7] O'Brien, Heather L. \& Elaine G. Toms (2008). What is User Engagement? A Conceptual Framework for Defining User Engagement with Technology. Journal of the American Society for Information Science and Technology, 59(6), 1-37. http://dx.doi.org/10.1002/asi.20801

[8] Mobile Marketing Association (2011b). Global Perspectives: The Smartphone User \& The Mobile Marketer. Retrieved from http://www.mmaglobal.com/files/mobileadvertising.pdf

[9] González, Z. \& Contreras, R. (2012). Apps como una posibilidad más de comunicación entre la marca y su público: un análisis basado en la valoración de los usuarios. Pensar la Publicidad. Revista Internacional de investigaciones Publicitarias, 6 (1), 81-100. Retrieved from http://revistas.ucm.es/index.php/PEPU/article/ view/38657, http://dx.doi.org/10.5209/rev_pepu.2012.v6.n1.38657

[10] IAB Spain Research. (2012). IV Estudio IAB Spain sobre Mobile Marketing: Informe de Resultados Septiembre de 2012. Retrieved from http://www.iabspain.net/mobile-marketing/

[11] Lee, E. \& Hahn, K. (2015). Tone of Writing on Fashion Retail Websites, Social Support, e-Shopping Satisfaction, and Category Knowledge. Clothing \& Textiles Research Journal, 33(2), 143159. http://dx.doi.org/10.1177/0887302X15568915
[12] Snyder, B. (2009, September 14). Marketers get wise, design mobile apps with a purpose. Advertising Age [Web log post]. Retrieved from http://adage.com/article/digital/marketers-wisedesign-mobile-apps-a-purpose/138974/

[13] Yul, U., Lee, H. \& Damhorst, M. (2012). Exploring Multidimensions of Product Performance Risk in the Online Apparel Shopping Context: Visual, Tactile, and Trial Risks. Clothing \& Textiles Research Journal, 30(4) 251-266. http://dx.doi.org/10.1177/ 0887302X12462059

[14] Nie, Y. \& Fortunati, L. (2013). Between Fashion and Technology: Investigating Mobile Fashion Applications. CIRN Prato Community IT Conference 2013: 28-30 october 2013 (pp.1-20). Prato Italy: CIRN-UCLA.

[15] Kawamura, Y. (2005). Fashion-ology: An Introduction to Fashion Studies. Oxford: Berg.

[16] Corbeta, P. (2007). Metodología y Técnicas de investigación social. Barcelona, Spain: Mc Graw Hill.

[17] Elósegui, T. (2013, February 10). Las claves del éxito en mobile marketing [Web log post]. Retrieved from: http://tristanelosegui.com/2013/02/10/las-claves-del-exito-enmobile-marketing/

[18] Mobile Marketing Association (2011a). Estudio de inversión en publicidad y marketing móvil en España 2011. Retrieved from http://www.marketing-movil-sms.com/wp-content/uploads/Estu dio-de-Inversión-en-Marketing-y-Publicidad-Móvil-2011-MobileMarketing-Association Vdefinitiva-1.pdf

\section{AUTHORS}

Z. F. Gonzáéz Romo PhD. in Advertising and Public Relations from the Autonomous University of Barcelona, Spain. Professor of Advertising and Public Relations at the University of Vic, Spain. Consultant in Advertising and Public Relations at the Open University of Catalonia, Spain. She has given lectures, seminars and workshops in the field of marketing and advertising in several countries and has published numerous articles and books. Member of the Digital Interactions Research Group (GRID), at the University of Vic. As a professional, she has her own Advertising Agency, and she work as Consultant for several companies in different countries. Accredited as Associate Professor (ANECA).

R. Contreras-Espinosa, is Lecturer at the Faculty of Business and Communication (University of Vic, Spain), where she also has worked on other aspects of the academic profession such as research and management. Coordinator of the Research Group on Digital Interactions (GRID) of UVic. Accreditation as Associate Professor (ANECA).

I. García Medina Lecturer in Marketing at the Caledonian University of Glasgow (UK). Area of interest in research: mobile marketing, digital marketing, digital communication, social media, e-branding. Bachelor of Communication Sciences (Universidad Complutense de Madrid, Spain) and Ph.D. in Marketing (University of Sophia - Antipolis, France) and International Relations (University of Vienna, Austria). As a teacher, Irene has previously taught Marketing and International Business Management at graduate level and master's degree in different Universities. As a professional, she has worked as Marketing Director and as Head of Communication and Promotion of CORDIS (European Commission, DGXIII, Luxembourg). Accredited as Associate Professor (ANECA).

Submitted 12 February 2016. Published as resubmitted by the authors 26 March 2016. 